In: Nicholas Saul, Simon J. James (Hg.): The Evolution of Literature. Legacies of Darwin

in European Cultures (Internationale Forschungen zur allgemeinen und vergleichenden

Literaturwissenschaft 152). Amsterdam at al.: Rodopi 2011, 299-317.

\title{
Evolutionary Psychology as a Heuristic in Literary Studies Katja Mellmann
}

\begin{abstract}
There has been a great deal of uproar about Darwinian approaches in literary scholarship. Statements range from enthusiastic prophecies of a new paradigm for literary studies to acrimonious scoldings of reductionism. Believing that the major challenge is first to find good questions to which evolutionary psychology might provide us with good answers, I outline and critically assess different veins of argumentation as revealed in recent contributions to the field. As an alternative to some simplistic mimeticism in present Literary Darwinism, I put forward the idea of evolutionary psychology as a heuristic theory that serves to resolve defined problems in interpretation and literary theory.
\end{abstract}

On the eve of Darwin's anniversary year, Style brought out a special double issue entitled 'An Evolutionary Paradigm for Literary Studies'. In the opening essay, Joseph Carroll describes evolutionary literary study as 'a distinct movement' which has emerged since the publication of his book Evolution and Literary Theory (1995) and is rapidly gaining in visibility and impact'. ${ }^{1}$ The subsequent contributions by 35 respondents, however, as well as Carroll's final rejoinder, make manifest that the distinctiveness of this 'paradigm' is rather precarious and that conceptions about the goals, range of applicability, and methods of evolutionary approaches sometimes differ greatly. The emergent consensus seems quite minimalistic; in summary it consists in the belief that the human sciences do have something to tell us literary scholars; that their theories and findings are not limited to providing rich topics for humanistic meta-perspectives ('The Rhetoric of Genetics') but are co-equal contributions within the general academic pursuit of knowledge which can indeed be applied.

1 Joseph Carroll, 'An Evolutionary Paradigm for Literary Study', Style, 48 (2008), 10335 (p.103). For a survey of the field see the collections: Biopoetics. Evolutionary Explorations in the Arts, ed. by Brett Cooke and Frederick Turner (Lexington: International Conference on the Unity of the Sciences, 1999); Literary Biopoetics, ed. by Brett Cooke (Interdisciplinary Literary Studies 2.2); Symposium: Evolution and Literature, ed. by Nancy Easterlin (Philosophy and Literature 25.2); Anthropologie der Literatur: Poetogene Strukturen und ästhetisch-soziale Handlungsfelder, ed. by Rüdiger Zymner and Manfred Engel (Paderborn: Mentis, 2004); The Literary Animal. Evolution and the Nature of Narrative, ed. by Jonathan Gottschall and David Sloan Wilson (Evanston: Northwestern University Press, 2005); Biological Constraints on the Literary Imagination, ed. by Katja Mellmann and Anja Müller-Wood (Studies in the Literary Imagination 42.2); also Heuristiken der Literaturwissenschaft. Disziplinexterne Perspektiven auf Literatur, ed. by Uta Klein, Katja Mellmann and Steffanie Metzger (Paderborn: Mentis, 2006). 
The idea of interdisciplinarity in literary scholarship is actually not as novel as all the noise about the evolutionary 'paradigm' might suggest. ${ }^{2}$ There have always been literary scholars who were open to ideas from other disciplines. Literary criticism has never simply had to deal 'with literature,' but also with its medium language, with what is represented in it, and with the communicative functions that literature performs within a given society. As such, literary theory has from its inception incorporated a number of context theories, including linguistics, philosophy/history of ideas, sociology/social history, iconography and history of media. While it is true that current psychology has for many years been restricted to a peripheral role in this respect, since a discipline largely dominated by behaviourism revealed few points of contact for questions relevant to literary scholars, the so-called 'cognitive turn' has crucially changed this situation. Methods of literary study have noticeably reinforced their efforts to elaborate an explicit psychological context theory, which now includes issues from the cognitive sciences and, after the emergence of evolutionary psychology, also adaptationist considerations. ${ }^{3}$ It is this reinforcement due to enriched

2 To name just a few instances out of the Grand Debate: Tony Jackson, 'Questioning Interdisciplinarity: Cognitive Science, Evolutionary Psychology, and Literary Criticism', Poetics Today, 21 (2000), 319-47; Bradley Bankston, Against Biopoetics: On the Use and Misuse of the Concept of Evolution in Contemporary Literary Theory (unpublished doctoral thesis, Louisiana State University, 2004); Brian Boyd, 'Getting it All Wrong: Bioculture Critiques Cultural Critique’, American Scholar, 75 (2006), 18-30; Jon Adams, Interference Patterns. Literary Study, Scientific Knowledge, and Disciplinary Autonomy (Lewisburg: Bucknell University Press, 2007), pp.77-99; Frank Kelleter, 'A Tale of Two Natures: Worried Reflections on the Study of Literature and Culture in an Age of Neuroscience and Neo-Darwinism', Journal of Literary Theory, 1 (2007), 153-89; Karl Eibl, 'On the Redskins of Scientism and the Aesthetes in the Circled Wagons', Journal of Literary Theory, 1 (2007), 421-42; Jonathan Gottschall, Literature, Science, and a New Humanities (New York: Palgrave McMillan, 2008); Maria E. Kronfeldner, 'Trigger Me: Evolutionspsychologie, Genzentrismus und die Idee der Kultur', Nach Feierabend: Zürcher Jahrbuch für Wissensgeschichte, 4 (2008), 31-45; Brian Boyd, On the Origin of Stories. Evolution, Cognition, and Fiction (Cambridge: Harvard University Press, 2009), pp.38492.

3 As sort of a constitutional charter of evolutionary psychology see John Tooby and Leda Cosmides, 'The Psychological Foundations of Culture', in The Adapted Mind. Evolutionary Psychology and the Generation of Culture, ed. by Jerome H. Barkow, Leda Cosmides and John Tooby (New York and Oxford: Oxford University Press, 1992), pp.19-136; and, more recently, 'Evolutionary psychology: Conceptual foundations', in The Handbook of Evolutionary Psychology, ed. by David M. Buss (Hoboken: Wiley, 2005), pp.5-67; also, as an important discussion on discrepancies with sociobiology, John Tooby and Leda Cosmides, 'The Past Explains the Present. Emotional Adaptations and the Structure of Ancestral Environments', Ethology and Sociobiology, 11 (1990), 375-424. 
opportunities that has occasionally been perceived as a 'new interdisciplinarity' or 'neo-naturalism,' rather than the dawn of a radically new paradigm. ${ }^{4}$

When in what follows I endorse evolutionary psychology as a valuable heuristic in literary studies, I do this in the sense of such a context theory, that is, as an ancillary discipline, the virtue of which consists in facilitating answers to questions that cannot be answered by text-immanent or cultural explanations alone. It is worth noting that the questions for which evolutionary psychology is consulted are themselves taken to arise from a genuinely literary epistemological interest. Accordingly, the first section of my essay is concerned to distinguish my own proposal from those Darwinian approaches that fail to identify a specifically literary problem in the first place, of which the adaptationist analysis is then the solution. In those approaches evolutionary psychology is accorded the status of a 'super theory' rather than that of a heuristic context theory. I shall particularly criticise the 'disguised and misplaced correspondence theory' by which those studies in practice equate literary representations with anthropological data. ${ }^{5}$ And I shall put forward the view that Darwin's evolutionary theory does not per se apply to artifacts (such as literary characters) but, a priori, only to living things, that is, to the 'human side' within the literary communication model (producer and receiver). As an alternative, then, I outline the concept of an 'anthropological model reader' in the second part of my essay. In this concept, evolutionary psychology serves as a reception-psychological heuristic which helps to shed light on traditionally obscure domains in our understanding of the literary reading process, and thus helps to resolve correlated problems of literary text interpretation. In the third section of the essay, I give a brief discussion on the feasibility of a general 'evolutionary literary theory' or, more precisely, of writing a biological prehistory of literature (as crucial part of the history of human evolution).

Mimetistic Tendencies in 'Literary Darwinism'

In his monumental Evolution and Literary Theory, Carroll originally presented a very broad spectrum of potential objects of study, which included both content and formal aspects of literature, and both realistic and symbolic

4 Cf. Mary Thomas Crane and Alan Richardson, 'Literary Studies and Cognitive Science: Toward a New Interdisciplinarity', Mosaic, 32 (1999), 123-40; Kelleter, 'A Tale of Two Natures', p. 155.

5 Marcus Nordlund, 'Consilient Literary Interpretation', Philosophy and Literature, 26 (2002), 312-33 (p.327). 
modes of representation. 6 The actual practice, however, has concentrated strongly on thematics and mimetic narrative. The preferred objects of examination are, for instance, male conflict behaviour in old epics and female mating behaviour in nineteenth century realism - in short: topics and texts that are especially well suited to supporting the findings of evolutionary psychology. ${ }^{7}$ A downright caricature of this procedure can be found in the popular book Madame Bovary's Ovaries, in which David and Nanelle Barash explain Madame Bovary's adultery and Othello's jealousy as resulting from the adaptive value of such behaviour in evolution. ${ }^{8}$ Of course, literary figures have neither wombs nor evolved psyches; their behaviour can thus not be explained in terms of biological evolution. But Barash and Barash are not literary scholars; their aim is an amusing illustration of evolutionary psychology for a general audience, and so there is little point in criticizing them here. A similar 'cookie-cutter' approach, however, can also be found in several studies by card-carrying literary scholars and thus give grounds for critical revision. ${ }^{9}$

A frequently heard argument in favour of a close comparison of human behaviour as depicted in literature with the predictions of modern psychology asserts that inaccurate interpretations can thus be avoided. By knowing about the 'Westermarck effect,' for instance, 'we can avoid erroneously importing mother/son incest into texts, such as Hamlet', as Carroll puts it. ${ }^{10}$ The so-called Westermarck effect refers to the Finnish anthropologist Edvard Westermarck's observation that closely living together during a particular period in early childhood leads to mutual sexual disinterest in adulthood (regardless of whether or not the persons in question are actually blood relatives). If we know about this innate best-bet

6 Joseph Carroll, Evolution and Literary Theory (Columbia: University of Missouri Press, 1995), pp.96-267.

7 See, for instance, Robin Fox, 'Male Bonding in the Epics and Romances', in The Literary Animal, pp.126-44; Jonathan Gottschall, The Rape of Troy: Evolution, Violence, and the World of Homer (New York: Cambridge University Press, 2008); Brian Boyd, 'Jane, Meet Charles: Literature, Evolution and Human Nature', Philosophy and Literature, 22 (1998), 1-30; Brett Cooke, 'Sexual Property in Pushkin's "The Snowstorm". A Darwinist Perspective', in Biopoetics, pp.175-204; Joseph Carroll, Literary Darninism. Literature and the Human Animal (Columbia: Routledge, 2004), pp.129-45; Joseph Carroll and Jonathan Gottschall, 'Human Nature and Agonistic Structure in Canonical British Novels of the Nineteenth and Early Twentieth Centuries. A Content Analysis', in Heuristiken der Literaturwissenschaft, pp.473-87.

8 David P. and Nanelle R. Barash, Madame Bovary's Ovaries: A Darninian Look at Literature (New York: Delacorte, 2005), pp.93-121, 14-37.

9 Jackson, 'Questioning Interdisciplinarity', p.341. Cf. also Steven Pinker, 'Toward a Consilient Study of Literature', Philosophy and Literature, 31 (2007), 161-77 (p.167).

10 Carroll, Evolution and Literary Theory, p.44. 
mechanism of incest avoidance, and if we also know that Hamlet (unlike (Edipus, for example) was not separated from his mother in his infancy, then we do not get up to any mischief. Likewise, says Carroll, in Emily Brontë's novel Wuthering Heights: although Catherine and her adoptive brother Heathcliff seem to manifest a passionate relationship, this cannot be, according to Carroll, because they have grown up together. But, alas, 'fictional representations just do not work that way,' as Alan Richardson laconically responded on Carroll's example: 'Like dreams, fictive works can bear a number of different relations to the rules and regularities of daily experience, often giving us the inverse of the lived world. If Emily Brontë is at liberty to people the Yorkshire moors with ghosts, why not incestuous foster-siblings as well?'11

Richardson generally questions Carroll's "Romantic claim that literary works manifest intuitive' knowledge that 'often outruns scientific understanding"' (p.562). I think, though, he is not being entirely fair to Carroll here, since literary figures of course are at least very similar in certain ways to actual human beings and, as Aristotle knew, literature indeed is at some level an imitation (mimesis) of human behaviour. Carroll's opinion that certain 'primal forces' at work the human mind as a product of natural selection can subliminally influence the poetic imagination and the 'figurative structures' of a literary text is in some respect only an extension of the hermeneutic maxim that the author does not necessarily perfectly understand his own text, and this is not automatically ridiculous. ${ }^{12}$ And yet Richardson hits a sensitive point in Carroll's argument, perhaps not by chiding his 'romanticism,' but certainly with the reference to the author's freedom of representative intention. Literary writers are not compelled to fashion verisimilar ('mimetic') representations. Hence, the argument that evolutionary psychology prevents erroneous interpretation collapses. Human nature as we understand it today can only serve as a rule of thumb for interpreting the behaviour of literary characters. Evolutionary psychology might tell us a lot about some tacit and unmarked default features of literary inventions or the reader's initial and subliminal expectations of them, and in these respects it might be useful cautiously to

11 Alan Richardson, 'Rethinking Romantic Incest: Human Universals, Literary Representation, and the Biology of Mind', New Literary History, 31 (2000), 553-72 (p.561).

12 Carroll, Evolution and Literary Theory, p.43; cf. also Carroll, Literary Darwinism, p.124, on 'the intuitive understanding of poets, novelists, and playwrights'; on the long tradition behind this maxim, see Lutz Danneberg, 'Besserverstehen. Zur Analyse und Entstehung einer hermeneutischen Maxime', in Regeln der Bedeutung, ed. by Fotis Jannidis et al. (Berlin: de Gruyter, 2003), pp.644-711. 
apply psychology at the level of representation. But evolutionary psychology cannot provide us with hard-and-fast knock-down criteria against readings inconsistent with its predictions - unless we want to end up with an impoverished notion of literary representation according to which the author is compelled to represent 'the world as it is'. ${ }^{13}$

The superficial realism that Richardson criticises in Carroll is unfortunately characteristic of many other attempts in applying a Darwinian perspective to literature. In such studies, the mimetic relationship between literary representations and biology is not only generally presumed but frequently even immensely strained by the sort of questions that are posed. Take as an example a study by Jonathan Gottschall in which he examines 1,440 folktales from forty-eight different cultures in order to refute the claim 'that European tales reflect and perpetuate the arbitrary gender norms of western patriarchal societies'.14 For what actually is the result of this study? When Gottschall discovers that the same stereotypes can be detected in all folktales he examined, he correctly refutes the 'prediction $[. .$.$] that [\ldots]$ an analysis of a culturally diverse sample will reveal diverse gender patterns' (pp.207-08). In testing this inferred hypothesis, however, he does not check the above-mentioned assumption about literature (that the tales 'reflect and perpetuate' a certain stereotype) but rather its constructivist premise (that this stereotype is an arbitrary western norm). Indeed, it seems he had not intended to do anything else - as becomes obvious when, after the job is done, he states with satisfaction that his own 'findings converge with emerging biosocial models of human behaviour and psychology' (p.219) while those of feminist literary criticism do not.

I do not however even suggest that Gottschall is wrong in preferring a biosocial to a (radically) constructivist theory of gender. My objection concerns rather the logic of his procedure. He claims to be testing a literarycritical hypothesis, but in fact he is testing an anthropological hypothesis using literary data. This strategy allows him to examine pieces of literature (folktales) just like any other piece of data, that is, without the need explicitly to justify - or at least evaluate - the material's evidentiary value and representativeness. That, of course, would be the first task in any rigorous

13 I want to stress that this statement holds only for interpretative assumptions concerning the internal coherence of the fictional world. The case is different with assumptions concerning external references (causal explanations, for example) as constructed by the literary critic, which draw on facts and knowledge beyond the textual givens in accordance with a prior 'theory of reality' (cf. Nordlund, 'Consilient').

14 Jonathan Gottschall: 'Quantitative Literary Study: A Modest Manifesto and Testing the Hypothesis of Feminist Fairy Tale Studies', in The Literary Animal, pp.199-224 (207). 
ethnological procedure drawing on literary or other sources. ${ }^{15} \mathrm{~A}$ detailed theory as to how folktales process (contain, manipulate, stylise, etc.) human universals (and, thereby, possibly indeed render a biological bias into a cultural norm) would not only have been indispensable here but might even have made a significant contribution to literary theory. Gottschall, however, misses this opportunity by tacitly presuming a mirroring relationship between biology and literature instead of recognising this complex and shifting relationship as the actual problem. When he proclaims that 'what ultimately drew most people to study literature was a desire to explore the behaviour and psychology of human beings,' he might well be informing us about his own motives, but surely he errs about the actual epistemological interest of the vast majority of literary scholars. ${ }^{16}$ The sceptical aloofness which Darwinian approaches to literature are often confronted with in their home discipline is mostly due to the (not entirely wrong) impression that those mimetistic approaches of 'proving that the universals are actually present in literature' or 'simplistically mapping' them onto literary texts do not really deal with literature but rather with the world behind it, and thus indeed miss the proper object of literary study. ${ }^{17}$

15 And is the first thing in, for instance, Michelle Scalise Sugiyama and Lawrence Sugiyama, 'A Frugal (Re)Past. Use of Oral Tradition to Buffer Foraging Risk', Studies in the Literary Imagination, 42.2 (2009), 15-41. I should add here that I do not at all consider it unreasonable in principle to use literature as a source for anthropological research. For the reasons mentioned above literary texts are not the most reliable but sometimes (for instance, if one examines historic or, like in Gottschall's study on Homer, The Rape of Troy, even prehistoric times) still the best sources for psychohistorical, and thus also anthropological questions. You simply need to know what you are doing. As long as an epistemological interest from anthropology is disguised into one of literary study, however, one does not know. Likewise, an interdisciplinary cooperation between literary scholars and psychologists (as, for instance, John A. Johnson, Joseph Carroll, Jonathan Gottschall, and Daniel Kruger, 'Hierarchy in the Library: Egalitarian Dynamics in Victorian Novels', Evolutionary Psychology, 6 (2008), 715-38) can be a good venture if the literary scholars in the team administer their expert knowledge about the specificities of literature and fiction. As long as they avoid applying themselves to precisely that, however, but rather hire out as semiskilled assistants in their neighbour disciplines, all meaning of interdisciplinarity gets lost.

16 Jonathan Gottschall and David Sloan Wilson, 'Introduction. Literature: A Last Frontier in Human Evolutionary Studies', in The Literary Animal, pp.xvii-xxvi (p.xix). Cf. also Carroll, Literary Darwinism, pp.124-25, who states with some enthusiasm that 'we have, for the first time, a situation in which the intuitive understanding of literary writers can converge effectively with the findings of empirical psychology.' Can it?

17 Jackson, 'Questioning Interdisciplinarity', p.341; Cf. Richardson, 'Rethinking Romantic Incest', p.569; also Nordlund, 'Consilient', p.315. 
In fairness, the mimetistic shortcut was not invented by evolutionary criticism. Let us return briefly to Carroll's incest example and see what his critic makes of it. Richardson believes that Romantic writers, when representing incestuous and near-incestuous relations, were not 'blindly responding to unconscious impulses or intuitions' but rather to 'the unique and specific character of Romantic-era culture and discourse,' for which he then cites some examples that reveal period-typical associationist reasoning, and in some case even a kind of an incest avoidance theory avant la lettre. ${ }^{18}$ To compare these historical discourses with our current understanding of the Westermarck effect, he says, helps to 'make sense of the two features of Romantic incest that critics have had most trouble accounting for: that incestuous desire, though idealised, nearly always ends tragically; and that this pattern holds equally for biological siblings, foster or adopted siblings, and various other co-socialized pairs' (p.570). I am quite ready to agree with this. But how, if so, can the Westermarck effect account for this without authors unconsciously responding to their intuitions about human nature, in just the manner Carroll suggested? Or, if Richardson means to replace the assumed implicit knowledge by more explicit forms of knowledge as attested in contemporary contexts, does he not stumble into the same mimetistic trap as Carroll (or at least touch it) by explaining literary inventions as broadly reflecting contemporary beliefs (a tacit assumption not uncommon in discourse-historical context studies)? To put it in his own words: if Brontë is at liberty to people the Yorkshire moors with ghosts, why not incestuous lovers living happily ever after? The fundamental freedom of representative intention in works of art applies for both implicit and explicit knowledge (if not even more strongly for the latter).

And lastly: how good is the question to which Richardson's final conclusion gives an answer? It seems to me that the Westermarck effect does not so much explain why incestuous and para-incestuous desire ends tragically in Romantic literature as why Romantic writers take up incest, literally or symbolically, when they want to depict an impossible love. ${ }^{19}$ To reverse

18 Richardson, 'Rethinking Romantic Incest', p.563. For similar instances within the German context see Michael Titzmann, 'Literarische Strukturen und kulturelles Wissen. Das Beispiel inzestuöser Situationen in der Erzählliteratur der Goethezeit und ihrer Funktionen im Denksystem der Epoche', in Erzählte Kriminalität, ed. by Jörg Schönert (Tübingen: Niemeyer, 1991), pp.229-81 (pp.266-73).

19 According to Niklas Luhmann, in the eighteenth century passionate love discourse was discovered as a means to manifest and stabilise the new social phenomenon of modern individuality Love as Passion (Liebe als Passion, Frankfurt: Suhrkamp, 1994, p.167-79). In this historic idea of love the beloved is expected wholly to share and reflect the lover's singular subjective view of life. Romantic love is thus by definition impossible in life. It is an affair of the imagination, of literature, of hope and fantasy; 
the question like that means to examine how and by what means an author achieves his/her goal (instead of ascertaining, in a surely redundant manner, the coherence of a literary representation with its general anthropological or culture-historical context). What cognitive programs can an author (consciously or unconsciously) count on in applying poetical techniques?20 It is this 'relationship between the structure of literary texts and their perceived effects'21 for which an expediently applied evolutionary approach, as a subdiscipline of cognitive poetics, can provide exciting new insights. In order to hypothesise reasonably about what innate dispositions are involved in (and how they shape) the understanding of literary texts we indeed require an explicit evolutionary-psychological heuristic.

Modelling the Correlation between Literary Artifact and the Human Mind: The Anthropological Model Reader

If psychology, as argued above, does not initially apply to artefacts but only to living things, our analytical focus has first to be shifted from the literary work per se to its recipient (including the author as his/her own first reader). However, since individual subjective experience is incommensurable, literary criticism normally deals with typified surrogates like the 'implied' reader of a text, an author's 'intended' reader, or an abstract or generalised 'model reader'. Discourse-historical studies in historic belief systems, habits of thought, cultural scripts and schemata, for example, implicitly construct a historical model reader in order to be able to speculate about how contemporary readers may have conceived certain issues in a

and literature addressed to this problem of modern love and individuality is very likely to end in tragedy on that account alone (cf. Karl Eibl, Die Entstehung der Poesie (Frankfurt: Insel, 1995), pp.125-33). Incestuous love thus is especially apt as a poetic symbol of this problematic, since it connotes both the total harmony of two individuals, the impossibility of fulfilment and, moreover, the sense of guilt still inhering in the attempt at radical self-realisation. The Westermarck effect readily explains incest as a symbol of the impossible, provoking strong feelings of discomfort and rejection in the reader and thus serving the author's purpose of a haunting depiction of unsolved problems; cf. also Titzmann, 'Literarische Strukturen', pp.273-77.

20 'Poetical techniques' here includes thematics (motifs, sceneries, plot schemata, etc.) as well as formal features. I think, Nordlund, 'Consilient', p.315, slightly mischaracterises positions critical of simplistic Darwinian interpretations when he imputes to them a 'fundamental primacy of poetics and formalist analysis over thematics'. Thematics is part and parcel of poetics, if literary content is not (indeed simplistically) understood as a reflex of reality but as a literary construct (based on and referring to reality, for sure, but in many different ways).

21 Reuven Tsur, Toward a Theory of Cognitive Poetics (Amsterdam: North-Holland Elsevier, 1992), p.1. 
text. $^{22}$ In a like manner we can construct an anthropologically typified model reader in order to determine more basic regularities of text comprehension. The anthropological model reader is thus a heuristic construct representing the evolved genotype of the human mind. It consists in all plausible adaptive algorithms summarised into a skeletal surrogate of the human psyche, that is, without the phenotypic 'flesh' of individual and cultural experience that characterises the empirical reader. ${ }^{23}$

So what is the heuristic construct of an anthropological model reader good for? In a first approach it can provide us insight into some basic responses that a reader is likely to show toward a particular passage and thus facilitates a deeper understanding of literary meaning, including innately biased associations, emotional effects, attention rousing, hierarchies of relevance. As Nancy Easterlin has for instance demonstrated using the example of the word 'home' in a passage from Wordsworth, drawing on evolutionary thinking strongly supports our interpretive task by enabling an 'empirically grounded speculation' about even unconscious processes in literary understanding and thus helps to disclose the full spectrum of literary meaning. ${ }^{24}$

Second, and equally important, assumptions about likely effects also bring us back to the text itself and allow for a closer understanding of how it is composed. Since adaptationist argumentation involves the specification not only of the adaptive behaviour itself but also of the selection pressure under which it has evolved, an evolutionary analysis always entails explicit assumptions about recurring situational features in correlation with which a particular behaviour has proved successful over the long course of evolution. That is, it informs us about a specific stimulus pattern which should be part of the releaser mechanism of the program in question and which, then, can be traced in the literary text. Thus, rather than searching for (redundant) analogies between the behaviour of fictional persons and actual human beings, we should pay attention to the potential isomorphisms between text structure and innate releasing schemata. Literary texts provide many structural features (formal and thematic ones) that approximate the abstract search formulas built in the 'situation detectors' of our

22 To take incest as the example: Titzmann, 'Literarische Strukturen', (p.230-31), refers to his concept of 'cultural knowledge' in order to decide whether a passionate relationship as depicted in a piece of literature would have been considered incestuous by the contemporaries.

23 Tooby and Cosmides, 'The Psychological Foundations', pp.73-77, provide detailed instructions how a good and solid adaptationist argumentation has to look like if it shall not issue into 'just-so stories'. Cf. also Pinker, 'Toward', p.175.

24 Nancy Easterlin, 'Voyages in the Verbal Universe. The Role of Speculation in Darwinian Literary Criticism', Interdisciplinary Literary Studies, 2 (2001), 59-73, (p.65). 
adaptations. ${ }^{25}$ Literary artifacts thus can be said to act as kind of a dummy stimulus $^{26}$ on our innate dispositions.

Let me, in order to illustrate how this view can serve as a fertile heuristic for literary study in some of its most genuine concerns, refer to my own work on the development of emotive literary strategies in German eighteenth-century literature. There has long been consensus on a tendency towards 'emotionalisation' in German Enlightenment literature. However, this finding was based primarily on the poetological self-descriptions of contemporaries rather than being systematically verified in the literary texts themselves. Hypothesizing about innately biased stimuli (such as, among many others, innate fear stimuli as found in the literary Sublime or innate 'appetitive' stimuli from habitat selection which constitute the locus amonus of Rococo poetry) thus turned out to be a good means to determine, and indeed even (approximately) quantify the emotional impact of a given literary text. ${ }^{27}$ Thus, having deployed an established psychological context theory to describe fundamental effects of certain kinds of text structures, we are able to reconstruct (and reassess) particular lines of development in literary history (a general increase in emotionalising techniques, modernist attempts at 'abstraction,' popularising tendencies).

Third, we can apply modern psychology to the historical concepts found in documents of reception or contemporary poetics in order to specify their particular psychological reference. This was my aim, for example, in examining Lessing's conception of the Aristotelian eleos. In comparing Lessing's descriptions of this dramatic affect with emotion programs that can be reasonably assumed from an evolutionary point of view, I found that his term of 'Mitleid' indeed refers to 'mercy,' i.e. an emotion evolved to foster pro-social activities, rather than (as it is often rendered today) to a general capability for 'empathy'. In a similar manner, Ed Tan and Nico Frijda have reconsidered the response of tears in literary sentimentalism. By observing that 'crying is a response to helplessness rather than specifically to grief,' they can describe the sentimental response as effected by an adaptive algorithm for submission, which in a work of art can be triggered by 'any

25 Cf. Leda Cosmides, and John Tooby, 'Evolutionary Psychology and the Emotions', in Handbook of Emotions, ed. by Michael Lewis and Jeannette M. Haviland-Jones (2nd edn, New York: Guildford, 2001), pp.91-115 (p.93).

26 Cf. Katja Mellmann, Emotionalisierung - Von der Nebenstundenpoesie zum Buch als Freund. Eine emotionspsychologische Analyse der Literatur der Aufklärungsepoche (Paderborn: Mentis, 2006), pp.42-78, and 'Literatur als emotionale Attrappe. Eine evolutionspsychologische Lösung des 'paradox of fiction", in Heuristiken der Literaturwissenschaft, pp.145-66; similarly, Clemens Schwender, Medien und Emotionen. Evolutionspsychologische Bausteine einer Medientheorie (2nd ed., Wiesbaden 2006 [2001]).

27 Mellmann, Emotionalisierung, pp.244-47, 338-44. 
major resolution in a conflict where the stakes are high,' and thus debunk another myth of 'empathic' emotion. ${ }^{28}$ An evolutionary heuristic thus enhances our understanding and analysis of historical discourse and cultural concepts.

For all these reasons I would strongly refute the frequently heard assumption that evolutionary theory, dealing with the general rather than the particular, cannot tell us much about individual periods, genres, authors, or literary works. ${ }^{29}$ Indeed it can, if - and that is essential - our initial questions focus on the specific. My critique of the studies mentioned above is not a criticism of their interest in the universally human (which I share) but of their failure to state interesting questions from the point of view of literary scholarship. ${ }^{30}$

Given that we have such questions as a starting point, however, we would deceive ourselves were we to believe that we could treat them without any regard to the universally human as described by the human sciences. Even 'when we, as historians, explain the particular, we always draw it into the scope of more general assumptions; if we did not, we would be unable to employ any concepts at all and would be dealing with nothing but miracles. '31 For instance, why is the open ending of a play 'open,' the supple rhythm of a poem 'supple,' the vivid and suspenseful depiction of a narrative event 'vivid,' and what actually is 'suspense'? What is it that we call 'tragic,' 'comic,' 'sentimental,' and so on? We constantly involve

28 Ed. S.H. Tan and Nico H. Frijda, 'Sentiment in Film Viewing', in Passionate Views: Film, Cognition, and Emotion, ed. by Carl Plantinga and Greg M. Smith (Baltimore: Johns Hopkins University Press 1999), pp.48-64 (pp.53-54). For general problems with the concept of empathy in the reception of literature see Mellmann, Emotionalisierung, pp.104-56, and Mellmann, "Objects of 'Empathy:" Characters (and Other Such Things) as Psycho-Poetic Effects', in Characters in Fictional Worlds, ed. by Jens Eder, Fotis Jannidis and Ralf Schneider (Berlin: de Gruyter, 2010), pp. 416-41.

29 Cf., for instance, Jackson, 'Questioning Interdisciplinarity', pp.329, 341, and Kelleter, 'Worried Reflections', pp.164-69.

30 Some 'Literary Darwinists' do not even seem to understand what this is. Joseph Carroll, for example, ('Rejoinder to the Responses', Style, 48 (2008), 308-70) accuses Karl Eibl and me of 'repeat[ing] the culturalist commonplace that the depiction of romantic love arose at a particular moment in the cultural history of Western Europe' (p.331), because we said that knowing about the biology of Romantic love and its occurrence in all cultures is important but not sufficient to answer the question why, 'on the ground of this general human experience, the sophisticated (predominantly literary) technique of self articulation and world depiction developed in the course of the eighteenth century' (Karl Eibl and Katja Mellmann, 'Misleading Alternatives', Style, 48 (2008), 166-71 (p.170, emphasis in the original)).

31 Eibl, 'On the Redskins', p.423; similarly, Jackson, 'Questioning Interdisciplinarity', p.423. 
psychological assumptions in our discourse about literature, since many of our concepts (both in ordinary language and literary terminology) are implicitly based on intuitive commonsense knowledge about the effects of certain literary features. Although we often use these terms as if they were referring to the textual properties themselves, they are in fact referring to mental states in response to those properties. ${ }^{32}$

Replacing such intuitive knowledge with adaptationist reasoning seems to me to be another major benefit we can derive from an evolutionary heuristic. Explicit evolutionary-psychological hypotheses on the derivation and precise function of such basic correlations between text structure and perceived effect not only enhance our interpretative skills but also open up wider questions of poetics and aesthetics. Brian Boyd, for instance, tried to determine text structures that an evolutionary account would predict to be capable of provoking laughter, and so contributed to a theory of literary humour. ${ }^{33}$ In a similar attempt, I described a particular strategy of fictionalisation as based on our adaptations for laughter and humour. ${ }^{34}$ Similarly, Lisa Zunshine explored the role that our capacity for mind reading and formulating both adaptive categories (animate/inanimate) and concepts (utility, essence) might play in literary reading in two of her books. ${ }^{35}$ And Karl Eibl, in Animal poeta, postulated the existence of an 'induction instinct' - an evolved cognitive tool for information gathering and experiential learning - that would account for several literary features such as the rhetorical devices of metaphor and comparison, various kinds of repetition (of motifs, sounds, metrical patterns, etc.), and narrative cohesion. ${ }^{36}$

32 See, for instance, the habit of handling suspense as a text property as criticised in Katja Mellmann, "Vorschlag zu einer emotionspsychologischen Bestimmung von 'Spannung", in Im Rücken der Kulturen, ed. by Karl Eibl, Katja Mellmann and Rüdiger Zymner (Paderborn: Mentis Verlag, 2007), pp.241-268 (pp.241-44).

33 Boyd, Brian, 'Laughter and Literature. A Play Theory of Humor', Philosophy and Literature, 28 (2004), 1-22.

34 Katja Mellmann, 'Das 'Spielgesicht' als poetisches Verfahren. Elemente einer verhaltensbasierten Fiktionalitätstheorie', in Literatur als Spiel. Evolutionsbiologische, ästhetische und pädagogische Aspekte, ed. by Thomas Anz and Heinrich Kaulen (Berlin: de Gruyter 2009), pp.65-86; also Mellmann, Emotionalisierung, pp.264-352, p.450-51.

35 Lisa Zunshine, Why We Read Fiction. Theory of Mind and the Novel (Columbus: Ohio State University Press, 2006); Strange Concepts and the Stories They Make Possible. Cognition, Culture, Narrative (Baltimore: Johns Hopkins University Press, 2008).

36 Karl Eibl, Animal poeta. Bausteine der biologischen Kultur- und Literaturtheorie (Paderborn: Mentis, 2004), pp.288-92; further elaborated in 'Eine Kuh ist eine Ziege. Zu den evolutionsbiologischen Wurzeln der Metaphorik', Der Deutschunterricht, 6 (2006), 4452, 'The Induction Instinct: Evolution and Poetic Application of a Cognitive Tool', and Ralph Müller, 'Interaction in Metaphor', Studies in the Literary Imagination, 42.2 (2009), 43-60, 61-77. 
Moreover, he suggested that a number of basic and very widespread patterns of plot structure (e.g., separation-and-reunion plots) are due to specific hardwired mental gestalt schemata that once guided the behaviour of our hunter and gatherer ancestors in an adaptive manner. ${ }^{37}$

Investigations of that kind, establishing correlations between basic constituents of (literary) texts and adaptive algorithms, can then again be used for a deeper examination of how a given work of art is based on (exploits, perhaps violates, etc.) those evolved dispositions in a specific manner. In addition, however, they bear with great impact on our understanding of how literature works on a fundamental level. Relating cognitive adaptations like mind reading, induction, natural categories and schemata with textual features contributes to exploring the fundamental 'range of techniques that allow the simulation to run properly on the human mind,' and thus prepares the ground for literary theory. ${ }^{38}$ As literary scholarship is by no means exclusively concerned with interpretation and literary history but also with explication of its object of study (the phenomenon 'literature'), it may well be asked to what extent an evolutionary heuristic can contribute to a general theory of literature. Does it provide new insights into what literature is, how it works, and where it comes from?

On the Origin(s) of Literature

To be sure, literature as we know it, as a vast and in itself heterogeneous component of cultural tradition in literate societies, cannot be called an 'adaptation' in the biological sense of the word. To do that one would at least have to recur to oral tradition and construct a typified surrogate conception of something especially characteristic of literature that could have already been present in ancestral times. In this spirit, there have been numerous attempts at describing the 'adaptive value' of literature or the arts in general. The problem with most of these suggestions, however, is that they are either not applicable to all forms of art/literature or not exclusive to art/literature. While it is reasonable to examine the evolutionary origins of certain features of art and literature, this should not be confused with determining the evolutionary origin of art or literature per se. The

37 Eibl, Animal poeta, pp.263-72; further elaborated in 'Epische Triaden. Über eine stammesgeschichtlich verwurzelte Gestalt des Erzählens', Journal of Literary Theory, 2 (2008), 197-208.

38 I owe this handy phrase to Keith Oatley and Mitra Gholamain, 'Emotions and Identification. Connections between Readers and Fiction', in Emotions and the Arts, ed. by Mette Hjort and Sue Laver (New York: Oxford University Press, 1997), pp.263-81 (p.273). 
assumption that 'the arts fulfill a vital adaptive function' suggests a distinct psychological design that was selected as a solution to a specified adaptive problem. ${ }^{39}$ To my knowledge, however, there have not yet been propositions suggesting how such a special cognitive design (responsible for all artistic or literary activities, and only for them) should look. And if such an assumption is to mean less than that, it is not an evolutionary explanation in the strict sense and thus not very informative; for everything we do is, in a sense, 'adaptive,' as we are members of a species that is still adapted well enough, on average, to people this planet. ${ }^{40}$

Narrative might be a more promising candidate for a potential cognitive adaptation in the literary field. Evidently, narrative is a human universal; also, there are indications that it develops as a distinct capacity in ontogeny; and telling stories and narrative thinking occur not only in written literature but throughout our everyday life. All these facts might hint at the possibility of a distinctly evolved cognitive feature. While most of the advocates of a biological adaptation 'narrative' content themselves with pointing to its ubiquity or the natural proclivity to a narrative organisation of information, Michelle Scalise Sugiyama was the first to attempt a clear-cut adaptationist account of narrative by determining a correlated selection pressure. ${ }^{41}$

39 Carroll, ‘An Evolutionary Paradigm', p.127.

40 Obviously, Carroll does mean less, when he says, for example, that '[i]f various cultural activities are 'biologically adaptive', and if the arts are among those activities, then the arts are 'biologically adaptive" (Carroll, 'Rejoinder', p.356), in order to refute Karl Eibl's and my demur that the arts are not a distinct biological adaptation. For rules of explanation see note 23 and Steven Pinker, How the Mind Works (London: Penguin, 1999), pp.525-26; cf. also Tooby and Cosmides, 'The Past', p.400, on 'two separate meanings for the word 'adaptive".

41 This natural proclivity often is related to neurological evidence according to which the way our brain processes experiential information and produces the sense of a self resembles narrative organisation. However, this would rather be a reason not to consider narrative as a distinct adaptation. For if the way verbal narrative is 'formatted' (cf. John Tooby and Leda Cosmides, 'Does Beauty Build Adapted Minds? Towards an Evolutionary Theory of Aesthetics, Fiction, and the Arts', SubStance, 30 (2001), 6-27 (p.24)) can be traced back to neural working principles, there is no need to additionally explain it as a special design. And inasmuch as narrative thinking involves higher degrees of narrative order, it overlaps with other adaptations (such as induction, causality, etc.), so that narrative rather seems to be a complex cultural congregation of innate dispositions than a distinct biological adaptation itself. For a more general evolutionary view on narrative without the correlation of a distinct cognitive design see H. Porter Abbott, 'The Evolutionary Origins of the Storied Mind: Modeling the Prehistory of Narrative Consciousness and its Discontents', Narrative, 8 (2000), 247-56, and Katja Mellmann, 'Voice and Perception. An Evolutionary Approach to the Basic Functions of Narrative', in 
According to her, narrative is an especially effective 'information storage and transmission system' that expedites inculturation and social learning in a species adapted to the 'cognitive niche'. ${ }^{42}$ This is a valid suggestion for an explanation at the 'ultimate' level, i.e. for an answer to the question how the assumed special design could have come into being, and as such distinguishes itself from the countless suggestions exposing only a general 'adaptiveness' of narrative. Whether narrative really relies on a distinct cognitive program (or if it is rather a contingent universal resulting from a plurality of innate algorithms that are combined similarly over and over again in all cultures) is anything but clear at the moment; but Scalise Sugiyama's pioneering considerations demonstrate in an exemplary manner how such questions can be pursued in future. ${ }^{43}$

The search for specifically literary adaptations, however, is not the only way that evolutionary psychology can contribute to literary theory. As may already have become evident, literature involves a large number of adaptations from many areas of human behaviour (environmental experience, emotions, social cognition, and so on) which are not especially related to literature, yet indeed seem to constitute its very core. ${ }^{44}$ John Tooby and Leda Cosmides, in their seminal essay 'Does Beauty Build Adapted Minds?,' have taken this as a starting point for explaining why at all we spend a significant amount of time engaged with fictions, which from a Darwinian standpoint at first seems to be a puzzling anomaly (p.7). In their view the pleasure we derive from reading may be due to the fact that certain textual features enable the execution of our adaptations in an 'organizational mode' and thus facilitate the ontogenetic development and adjustment of our phylogenetic adaptations. ${ }^{45}$ They 'think that the task of organizing the brain both physically and informationally over the course of the lifespan is

Toward a Cognitive Theory of Narrative Acts, ed. by Frederick Aldama (Austin: University of Texas Press, 2010), pp. 119-140.

42 Scalise Sugiyama, Michelle, 'Reverse-Engineering Narrative: Evidence of Special Design', in The Literary Animal, pp.177-96 (p.190). The essay is only one in a series of articles of hers exploring the incorporation of adaptive information in hunter-andgatherer folklore; see her own bibliography in Scalise Sugiyama and Sugiyama, 'A Frugal (Re)Past'.

43 For the most recent study on this topic (too recent to be included here) see Boyd, On the Origin.

44 Cf. also Pinker, How the Mind Works, pp.538-43.

45 Tooby and Cosmides, p.16. - The idea of an 'organizational mode' of performance was adopted in literary studies by Eibl, Animal poeta, pp.277-352; Karl Eibl, 'Adaptationen im Lustmodus. Ein übersehener Evolutionsfaktor', in Anthropologie der Literatur, pp.30-48; Mellmann, Emotionalisierung, pp.69-74; Karl Eibl, 'Zwei Kulturen? Zwei Denkweisen und ihre biologischen Ursprünge' in Im Rücken der Kulturen, pp.3148; Mellmann, 'Das Spielgesicht'. 
the most demanding adaptive problem posed by human development. Building the brain, and readying each of its adaptations to perform its function as well as possible is [...] a vastly underrated adaptive problem' (p.14) which, in their opinion, was resolved by evolving specialised pleasure circuits that function as 'motivational guidance systems' (p.16) to provoke such seemingly pointless behaviours as play and fictional engagement. In short, literary works are so appealing because they provide occasions for an intrinsically rewarded organisation of our neurocognitive apparatus (pp.1318). ${ }^{46}$

This is not so far away from Steven Pinker's suggestion that the arts are kind of cheesecake for the mind in that they are simply 'pressing our pleasure buttons' ${ }^{47}$ But Tooby's and Cosmides' additional assumption of 'an

46 For a similar consideration see Boyd's conception of art as a form of 'cognitive play' (On the Origin, pp.80-98, 381). Boyd's critique of Tooby's and Cosmides' account ('Evolutionary Theories of Art', in The Literary Animal, pp.147-76 [pp.169-70]) relies on several misconceptions: (1) His objection that according to their theory 'interest in art should taper off beyond childhood' (Boyd, p.169) disregards that they explicitly speak of '[b]uilding, readying, and maintaining the brain' (Tooby and Cosmides, p.14, my emphasis). (2) Further, he criticises that they 'concentrate strongly on representation, which is only one component of art', and that 'their hypothesis would not account for music', for instance (Boyd, p.169), while they repeatedly mention music among their examples (cf. Tooby and Cosmides, pp.17-18, 25). (3) A really absurd objection is that they 'ignore actual experience' (Boyd, p.170) by overemphasising learning processes mediated through fiction. Yet their question is not how learning works (with the wrong answer: exclusively by fiction) but why we like fiction (answer: because it facilitates pleasure-rewarded learning effects). Learning through fiction is thus by no means considered to compete with or displace other learning processes but is in fact reasonably put in conjunction with them (cf. Tooby and Cosmides, p.12). (4) Finally, Boyd thinks that their account for the 'proximate mechanism, our immediate motivation for fiction, is lost in fog', for 'untruth per se does not make us attend to stories' (Boyd, p.170). But this was not their argument. Fictions need to match specified preference systems (cf. Tooby and Cosmides, pp.13-14) - that is the crucial criterion according to their theory, rather than 'untruth' (which is only one of several possible conditions that allow for a riskless execution of immature programs). And the proximate motivation for our involvement with fiction is pleasure. For a critical discussion of Boyd's own suggestion see Pinker, 'Toward', pp.173-77.

47 Pinker, How the Mind Works, p.525. It might seem odd to some that I see Tooby's and Cosmides' analysis as so similar to Pinker's, since theirs is often taken as representing the 'functional' and his the 'byproduct' position. However, Tooby and Cosmides themselves 'still consider the byproduct hypothesis to be the default hypothesis, with a great body of logic and evidence in favor of it', and Pinker's 'argument [...] a powerful one,' that 'successfully explains many features of the arts,' but also they think 'that there is much that it leaves unexplained' (p.11), namely those motivations for art and fiction that cannot be explained immediately by particular preferences 
entire suite of developmental adaptations' 'that were selected to involve humans in aesthetic experiences and imagined worlds' makes an important amendment to the picture drawn by Pinker, as their hypothesis accounts for the outstanding significance of play, imagination, fiction, literature, and so on, within human culture. ${ }^{48}$ Phenomena like these then appear to be more than mere by-products of human evolution: they are paradigmatic, albeit interchangeable, expressions of a fundamental characteristic of our species. That said, though, Tooby and Cosmides resist the temptation to propose a fundamental impulse to produce fiction (or 'the arts,' narrative, creativity, imagination, etc.) in the sense of a distinct cognitive program..$^{49}$ Rather, the 'additional layer of adaptations' supposed by them consists in a heterogeneous number of discrete adaptations all across human behaviour, including, for example, motoric activities like dancing as well as cognitive ones. ${ }^{50}$

In conclusion: even if evolutionary contributions to literary theory will presumably rarely achieve the form of straightforward explanations of literary phenomena, the evolutionary perspective may indeed, in time, greatly enhance our general understanding of literature by specifying its particular place within human behaviour as a whole. ${ }^{51}$ The fact that evolution can account for literature only from multiple angles need not to be considered a deficiency but can also be seen as an advantage, because it draws attention to the multi-factorial complexity - that is, the very nature of literature. Having once acknowledged that there is no such story as 'The Emergence of Literature in Human Evolution' but rather an entire range of evolutionary histories of various proto-forms of literature, ${ }^{52}$ we can set out

pertaining to fully developed algorithms (but necessitate an indirect explanation by additional preference systems guiding the development and organisation of those algorithms). Conversely, Pinker only 'proposed that many of the arts may have no adaptive function at all' and even contemplates that, '[u]nlike other forms of art, fiction lends itself to at least a prima facie case that it is also an adaptation' (Pinker, 'Toward', p.171, my emphasis).

48 Tooby and Cosmides, 'Does Beauty', p.14, p.11.

49 I wonder why Boyd, On the Origin, maintains that '[a] rt in this broad sense [of cognitive play] is a human adaptation' (p.381, emphasis in the original) and that there are 'features common to all forms of art' (p.69), although he is actually well aware of the multiple origins of art behaviours and in fact sketches out in his book a multilayered and rather complex evolutionary history of art, fiction and storytelling.

50 Tooby and Cosmides, 'Does Beauty', p.11.

51 Cf. also Boyd, On the Origin, pp.384-85.

52 Cf. Lorenz Welker, 'Kategorien musikalischen Verhaltens in evolutionärer Perspektive. Geschlechtsdifferenzen, Universalien und ein Schichtenmodell musikalischer Wahrnehmung', in Im Rücken der Kulturen, pp.271-90, who distinguishes several proto-forms of music which he takes to have emerged from different 
to write those many stories. That, surely, is a worthwhile interdisciplinary research programme. ${ }^{53}$

behavioural domains but can all be said to be among the ancestors of what today we call 'music'.

53 Thanks to Karl Eibl and Nancy Easterlin for their comments on a draft version of this essay. 